\title{
Uma capital amazônica entre a espera do rio e as promessas da estrada (1944-1988)
}

DOSSIER RIOS E CIDADES: ARAGUAIA

\section{Sidney Lobato}

Professor da Universidade Federal do Amapá. Doutor em História Social pela Universidade de São Paulo [USP]. Pós-doutorado na École des Hautes Études en Sciences Sociales [EHESS-Paris], com bolsa da Capes. Macapá [AP] Brasil <lobato.sidney@yahoo.com.br>.

\section{Resumo}

Neste artigo ${ }^{1}$ analisamos as políticas que, entre 1944 e 1988, tiveram por objetivo multiplicar e fortalecer as conexões entre Macapá e os demais núcleos urbanos do extremo-norte do Brasil. A partir da leitura de fontes como jornais, relatórios de governo, censos e outros, foi possível inferir que, apesar do discurso de valorização das estradas em detrimento dos rios, estes continuaram sendo importantes conectores socioeconômicos, viabilizando não apenas o tráfego das embarcações governamentais, mas também o dos regatões, que neste período foram responsáveis por grande parte do abastecimento da capital amapaense. Destacamos o permanente estado precário das estradas locais, assim como a insuficiência dos meios de transporte terrestres e fluviais providos pelo governo.

\section{Palavras-chave}

Cidade. Rios. Estradas. Rede urbana. Amazônia.

\section{An Amazonian capital between waiting for the river and the road promises (1944-1988)}

\begin{abstract}
In this article we analyze the policies that, between 1944 and 1988, aimed to multiply and strengthen the connections between Macapá and other urban centers of the extreme-northern Brazil. From reading sources such as newspapers, government reports, census and others, it was possible to infer that despite the speech of enhancement of roads over the rivers, they remained important socioeconomic connectors, enabling not only the traffic of government vessels, but also of "regatões", which in this period accounted for much of the supply of Amapá capital. We highlight the permanent precarious state of local roads, as well as the failure of the land and river transportation provided by the government.
\end{abstract}

\section{Keywords}

City, Rivers. Roads. Urban network. Amazon.

\footnotetext{
${ }^{1}$ Este artigo é resultado da pesquisa de pós-doutorado "Alterações recentes na rede urbana da Amazônia oriental: a transformação de Macapá em cidade média (1944-1987)", realizada na École des Hautes Études em Sciences Sociales (Ehess-Paris), entre 2015 e 2016, com bolsa da Capes.
} 


\section{Introdução: Macapá, nascimento e renascimento}

Macapá, que atualmente é a capital do estado do Amapá (situado no extremo-norte do Brasil), foi o primeiro investimento urbano feito pelos representantes do Ministro Português Sebastião José de Carvalho e Melo (mais tarde Marquês de Pombal) no Estado do Grão-Pará e Maranhão. A elevação de Macapá à categoria de vila, no início de 1758, também foi o marco inaugural do "estilo pombalino", onde um modelo de cidade parcialmente regular (manuelino e renascentista) foi substituído por outro totalmente simétrico e equilibrado (Araújo \& Moreira, 1999, p. 173-196). Além de servir de sentinela do domínio português na foz do Amazonas, Macapá deveria ser um símbolo da civilização "branca" constituída por açorianos, com uma economia baseada na agricultura, na pecuária e na indústria. Mas, o que aconteceu na Amazônia não foi uma simples reprodução do estilo de vida lusitano. No início do século XIX, a "Província dos Tucujú", bem como toda a região do GrãoPará e Maranhão, abrigava uma variedade de povos e culturas que deu origem a muitas misturas socioculturais.

Quase um século depois de sua fundação (em 1856), Macapá recebeu o título de "cidade". Este núcleo urbano passou a funcionar como um entreposto comercial, ligando coletores de látex da "região das ilhas" a Belém, onde ocorriam as trocas comerciais (Reis, 1953, p. 57). A economia macapaense era então baseada principalmente na produção da borracha. A exploração deste produto fez com que ocorressem várias mudanças na rede urbana da Amazônia: a intensificação das relações entre os centros populacionais; aceleração do tráfego, possibilitado pela navegação à vapor; a modernização das maiores cidades da Amazônia; a consolidação de Belém como metrópole regional; e) e o surgimento de Manaus como um centro regional que passou a competir com Belém. Posteriormente, a Amazônia foi dividida em duas sub-regiões: a ocidental, centrada em Manaus, e a oriental, polarizada em Belém (Weinstein, 1993).

Esta divisão não alterou o perfil básico da região que era caracterizado pela macrocefalia urbana. Segundo alguns estudos, o grande desnível demográfico e urbano entre as metrópoles regionais e os demais centros populacionais amazônicos foi agravado pela longa crise da borracha, iniciada em 1912. Além disso, o consequente êxodo dos seringais provocou um aumento significativo nas populações de Belém e de Manaus. Em 1960, estas cidades concentravam mais de 50\% dos habitantes dos estados do Pará e do Amazonas. Assim, a crise da economia da borracha trouxe profundas alterações demográficas para a Amazônia. Lobato Correa (1987, p. 149-150) afirma que, nesta região, durante vários anos depois da crise da produção gomífera, testemunhou-se uma redução drástica das populações das pequenas cidades e que até mais tarde, entre 1940-1950, esses núcleos demonstravam ainda um crescimento de população abaixo da média nacional.

No entanto, esta tese relativa aos efeitos demográficos da longa depressão da economia da borracha não deve ser estendida sem ressalvas a toda Amazônia. Isto porque, ainda na primeira metade do século XX, alguns centros urbanos experimentaram rápidos crescimentos populacionais. Foi o caso de Marabá que cresceu exponencialmente graças à exploração de castanha do Brasil. Foi igualmente o caso de outras cidades, como as que ganharam o status de capitais dos territórios federais criados em 1943. Essas novas capitais cresceram rapidamente em decorrência de suas funções políticas e administrativas. Isto prova que a urbanização na Amazônia não pode ser explicada apenas pela abordagem economicista. Segundo os geógrafos John Browder e Brian Godfrey (2008, p. 13-39), esta região tem muitos espaços "super urbanizados", onde o nível de urbanização e a taxa de crescimento demográfico muito excedem os índices de desenvolvimento econômico e tecnológico. Eles argumentam, além disso, que a urbanização na fronteira amazônica frequentemente não acompanha o ritmo do desenvolvimento econômico regional, pois ela é quase sempre consequência da intervenção de um Estado centralizado e modernizador.

Em meados do século XX, setores estatais planejavam mudar o antigo perfil de ocupação do território brasileiro, através do controle dos fluxos demográficos (Cabreira, 1996). 0 governo de Getúlio Vargas pretendeu direcionar a migração para a enorme hinterland brasileira, com o objetivo de corrigir o problema da concentração populacional na faixa costeira. Áreas de fronteira disputadas durante longos períodos eram objeto de especial preocupação do governo federal. Este foi o caso do Território Federal do Amapá (que é estado desde 1988), cujas terras foram contesta- 
das ao longo de muitas décadas, por portugueses (depois brasileiros) e franceses. Para o governo do presidente Vargas, a definitiva incorporação nacional dos "sertões" teria o efeito de fazer a fronteira econômica enfim coincidir com a fronteira política (Nunes, 1950, p. 29).

Macapá, no início de 1944, foi elevada à condição de capital do Território Federal do Amapá. No entanto, naquele momento, este núcleo populacional era apenas um aglomerado de algumas centenas de habitantes, empobrecidos em decorrência da crise da borracha da Amazônia (Lombaerde, 1987). As construções feitas pelo governo territorial trouxeram novo ânimo a então fraca economia local. Arthur Miranda Bastos, que foi Diretor de Divisão de Produção em 1947, escreveu que o governo do Amapá tinha tentado, logo depois de se instalar, apagar todos os vestígios de deterioração da nova capital por meio da construção novos prédios para abrigar os novos funcionários, removendo o mato de ruas e praças, carregando toneladas e toneladas de cimento, tijolos, telhas, madeira, ferramentas, máquinas, todas as coisas necessárias para dar a Macapá o aspecto de uma bela cidade (Bastos, 1947, p. 6-7). 0 nascimento desta "Macapá moderna" foi apresentado como um forte símbolo da vitória humana sobre uma aparentemente incontrolável natureza. De acordo com o discurso oficial, a ordem social havia superado a natureza e o homem, até então submisso aos caprichos da floresta, teria finalmente se tornado capaz de impor ao meio as suas regras.

\section{Contrastes e conexões entre Macapá e os demais núcleos amapaenses}

Macapá apresentava-se como lugar atrativo para moradores de municípios que receberam poucos investimentos para ampliar e melhorar seus serviços de saúde, educação, assistência social, infraestrutura urbana e outros. Tornou-se recorrente, ao longo das décadas aqui estudadas, o governo territorial suprir esporadicamente as demandas das populações interioranas por meio do deslocamento de equipes de atendimento para a realização de missões rápidas ou por meio do translado de doentes para a capital, principalmente, em pequenas aeronaves².

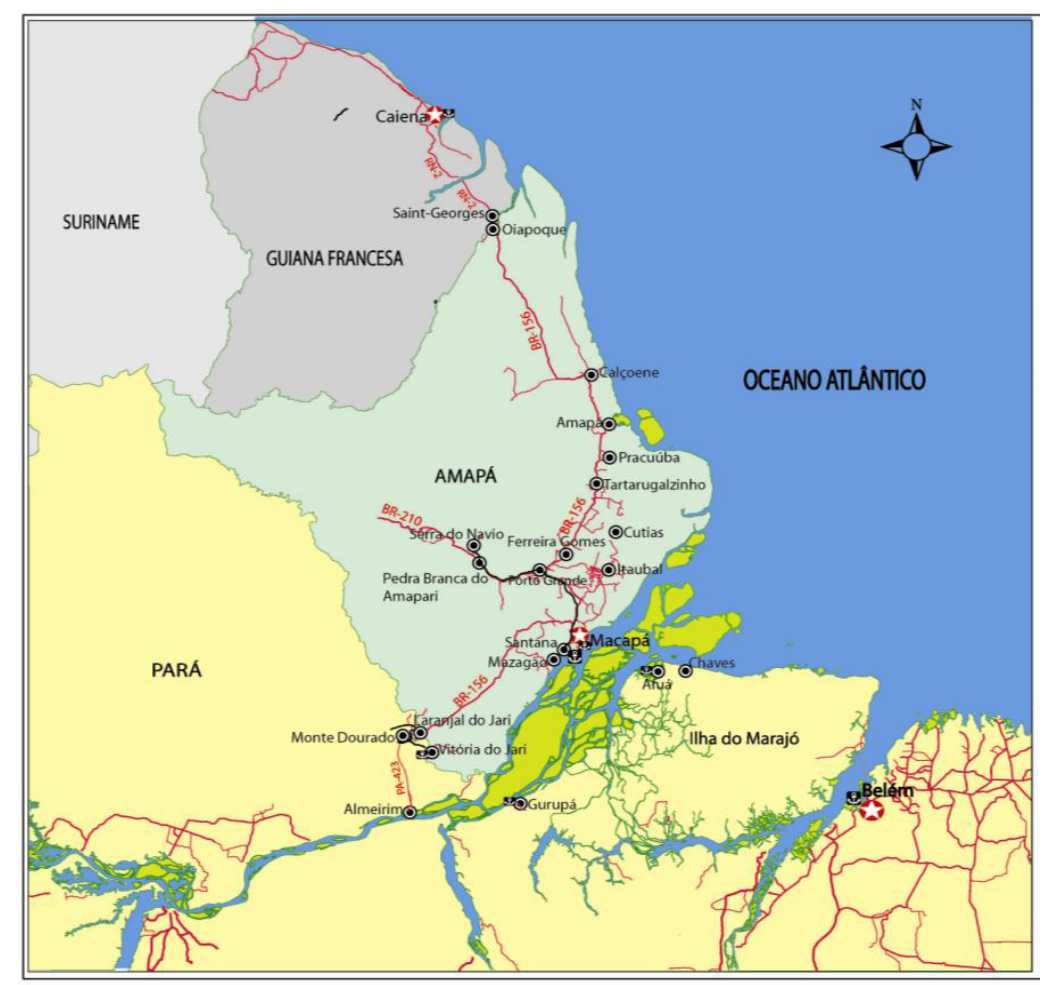

Figura 1. Mapa da rede urbana polarizada em Macapá. Fonte: Santos, 2012, p. 109.

Ao lado de suas precaríssimas redes de serviços públicos, as municipalidades interioranas contavam com atividades econômicas que, em geral, ofereciam, além de poucas oportunidades de trabalho remunerado, baixíssimos e instáveis rendimentos. A baixa densidade econômica e as dificuldades de navegação (em decorrência dos baixios, das correntezas e pororocas) faziam com

\footnotetext{
${ }^{2}$ Ver, por exemplo: Assistência às populações do interior. Nôvo Amapá. № 1484, de 07 de julho de 1968, p. 6.
} 
que as localidades da parte norte da costa amapaense contassem com uma pequena frequência de grandes e médias embarcações. Aí o abastecimento era algo mais incerto ou irregular do que no restante do Território (IBGE, 1966, p. 38).

Vilas, aldeias indígenas, garimpos e povoados ribeirinhos eram lugares cujos contrastes e interações sociais faziam do vale do rio Oiapoque o eixo de uma sociabilidade muito complexa. Segundo Alfredo Gama, era "na calada da noite" que os "creolos" desciam o Camopi e atravessavam o Oiapoque para, na sua margem brasileira, negociar o ouro com comerciantes que já estavam a sua espera. Quando não, os comerciantes enviavam expedições às minas francesas. Uma vez flagradas, estas eram detidas e suas mercadorias confiscadas pelos aduaneiros. Estes, segundo o autor, por mais "camaradagem" que tivessem, não perdoavam ninguém (Gama, 1947, p. 74-75). No período aqui enfocado, a influência de Macapá sobre as sociedades dos municípios de Oiapoque e Calçoene era muito frágil. Esses municípios abrigavam atividades econômicas como: um extrativismo vegetal diversificado, produção pesqueira destinada principalmente ao consumo local e garimpagem de baixo rendimento. A maior parte das transações comerciais oiapoquenses era feita com Belém. A Colônia de Clevelândia, além da função militar, oferecia assistência médica à população de Oiapoque. Por outro lado, os estabelecimentos comerciais de Calçoene também comerciavam direta e predominantemente com a praça belenense (IBGE, 1957, p. 24, 42).

No município de Amapá, à margem dos lagos Duas Bocas e Novo, achava-se uma população que se dedicava à agricultura e à pesca. Segundo o Atlas do Amapá, inicialmente os moradores desta área se dedicaram ao abastecimento de farinha d'água e pescado (principalmente pirarucu e tucunaré, retirados dos maiores, mais numerosos e piscosos lagos amapaenses) aos criadores de gado locais. Com o crescimento da demanda, várias firmas comerciais instalaram-se no Araguari (Restauração e outras) e passaram a vender sua produção de farinha e pescado para as cidades de Amapá, Macapá e Belém (IBGE, 1966, p. 22, 26 e 30).

Mas, a principal atividade econômica de Amapá era a pecuária. 0 vale do Araguari (que, aliás, cortava também o município de Macapá) era um dos mais importantes eixos de criação de gado do Território Federal do Amapá. Aí existiam diversas fazendas dispersas, sem limites fixos e cujos proprietários, em geral, eram parentes. Em termos de produção pecuarista, rivalizavam com esta área os vales dos rios Pedreira, Macacoari e Gurijuba (também locais de fazendas). Porém, segundo o Atlas do Amapá, a zona mais importante da pecuária amapaense era aquela que ia do norte do Araguari (próximo ao Aporema) até o vale do Amapá Grande, incluindo a região dos Lagos. Antes da criação do Território, as fazendas aí existentes possuíam um rendimento baixíssimo. A carne era consumida localmente (o que incluía os garimpos) ou vendida para a Guiana Francesa que, também segundo o Atlas, "absorvia grande parte do comércio da região, associado à lavra de ouro no norte do Território". Uma vez criado o Território, seu governo passou a investir no melhoramento do rebanho amapaense, oferecendo aos fazendeiros assistência técnica e reprodutores zebus. Em geral, o gado era doentio (sem influência de fora, sofria degenerescência) e desnutrido, tipo chamado "pé duro", que, por ser muito magro, era igualmente apelidado de "canela de vidro". Após a criação do Território, os reprodutores "pés duros" foram castrados e os zebus foram inseridos para a mestiçagem (IBGE, 1966, p. 32).

Em Mazagão, destacavam-se os barracões, que em muitos lugares ainda financiavam a produção (IBGE, 1957, p. 39). A pequena cidade de Mazagão, dada a grande proximidade, estabelecia predominantemente trocas com Macapá. Quanto ao resto do município, as suas atividades se dividiam entre a área de influência de Macapá e de Belém. A produção de peles de animais silvestres (veado, jacaré, jaguatirica, etc.) era toda individual e canalizada para as chamadas casas belenenses de comércio. A pesca destinava-se quase exclusivamente à subsistência familiar. A produção extrativa animal (produção de peles de animais silvestres, pesca, etc.) era muito inferior à vegetal.

De Mazagão (vales do Jari, Cajari, Maracá e Anauerapucu ou Vila Nova) provinha $90 \%$ da castanha produzida no Território. Esta produção, assim como a da borracha e a da madeira (sobretudo andiroba e macacaúba, exportadas direta e principalmente para Portugal), era majoritariamente controlada por empresas sediadas em Belém. Segundo o Atlas do Amapá, tais empresas controlavam principalmente as "colocações" dispostas ao longo da parte facilmente penetrável e navegável dos baixos cursos dos rios. Contudo, no vale do Anauerapucu (Vila Nova) o controle do comércio ainda 
era exercido por diversos comerciantes, enquanto os médios e altos vales (do sul amapaense) eram dominados por balateiros, que eram aviados avulsamente e que aí trabalhavam por conta própria. Porém, como estes não dominavam os transportes, não tinha muita liberdade para escolher a quem vender a produção. Ademais, em Mazagão (que era o segundo município amapaense em produção agrícola), a agricultura era praticada sobremodo nas margens dos rios Amazonas e Vila Nova, uma vez que as empresas comerciais controladoras de grande parte dos demais rios estavam mais interessadas no extrativismo vegetal (IBGE, 1966, p. 30 e 34). Por meio destes dados, podemos inferir que a polarização exercida por Macapá não era absoluta. Isto fica demonstrado no seguinte quadro de fluxos comerciais, que sistematiza um conjunto amplo de informações:

Quadro 1. Fluxos comerciais da rede sub-regional.

\begin{tabular}{|c|c|c|c|}
\hline Produto & Origem & Destinação Principal & $\begin{array}{c}\text { Destinação } \\
\text { Secundária }\end{array}$ \\
\hline Peixe & Amapá & Macapá & Belém \\
\hline Peixe & Macapá & Belém & Macapá \\
\hline Castanha do Brasil & Mazagão & Belém & \\
\hline Borracha & Mazagão & Belém & Macapá \\
\hline Carne bovina & Amapá & Caiena & Macapá \\
\hline Carne bovina & Marajó & Belém & \\
\hline Carne bovina & Macapá & Macapá & \\
\hline Farinha de mandioca & Amapá & Macapá & Suriname \\
\hline Farinha de mandioca & Belém & Macapá & Inglaterra \\
\hline Madeira & Mazagão & Portugal & \\
\hline Manganês & Macapá & EUA & \\
\hline Produtos industriais & Belém & Macapá & \\
\hline Produtos industriais & Macapá & Todos os municípios do Amapá & \\
\hline
\end{tabular}

Fonte: Serviço de Estatística do Território Federal do Amapá.

Além de demonstrar que a produção dos municípios interioranos não escoava toda para a capital amapaense, este quadro deixa claro que a exportação territorial nem sempre tinha Belém como destino, podendo ir diretamente para outros países. Era o que ocorria principalmente que a produção dos chamados grandes projetos. Em 1967, o empresário estadunidense Daniel Ludwig iniciou seus investimentos no vale do rio Jari, onde, em 1978, foi instalada uma fábrica de celulose, transportada diretamente do Japão. Mas, a empresa Jari Florestal e Agropecuária foi nos seus primeiros anos principalmente um complexo madeireiro e de criação de gado. Em 1982, o empreendimento foi vendido para o grupo Caemi, que era proprietário da Icomi.

No início da década de 1940, a Indústria e Comércio de Minérios S. A. (Icomi) era uma modesta firma constituída em Belo Horizonte. Em 1947, ela ganhou a concessão para fazer a prospecção e a exploração das imensas jazidas de manganês descobertas na área central do Território Federal do Amapá. Entre 1951 e 1953, a Icomi realizou uma série de esforços no sentido de se capitalizar para dar início a sua grande empreitada no Amapá. Tal empresa precisava de uma ampla infraestrutura para tornar possível a exploração e escoamento da produção manganífera amapaense. Esta infraestrutura foi dividida em três seções: a) área de mineração (vila de Serra do Navio e área de extração); b) a ferrovia (que transportava o minério); c) e o Porto de Santana (distrito da capital, distante dela cerca de $20 \mathrm{~km}$ ), onde terminava a ferrovia e de onde o minério saía, em navios, para o exterior (H. J. Cole Associados S.A, 1979, 22). No quadro do comércio internacional, a exportação 
de manganês era feita para os EUA (65\% aproximadamente), o Reino Unido (10\%), Alemanha Ocidental $(8,6 \%)$ e etc. ${ }^{3}$

Agricultura amapaense concentrava-se em Macapá, onde se localizavam 68\% da área cultivada do Território. Este era muito dependente de importações, pois a produção agrícola estava voltada principalmente para a subsistência, com margens de comercialização muito estreitas. 0 Atlas do Amapá descreve tal quadro com as seguintes palavras: da produção agrícola "nada se exporta", pois "ao contrário, contrário, há necessidade constante de importação de gêneros alimentícios provenientes do vizinho estado do Pará, sobretudo importação da indispensável farinha d'água". Ele ressalta que mais da metade da população amapaense vivia em área urbana e que $57 \%$ dela era inativa. Além disso, afirma que a rudimentar técnica de produção não permitia ao agricultor atender à demanda existente e que "pode-se dizer que apenas nas áreas propriamente agrícolas do município de Macapá e de pouco lugares de Amapá e de Mazagão, há um excedente comercial mais ou menos regular na produção agrícola". Esse maior desenvolvimento agrícola na parte central do Território tinha relação direta com a proximidade da capital, o maior mercado consumidor aí existente. Foi a existência deste mesmo mercado que determinou a localização planejada de famílias de agricultores em núcleos coloniais, por iniciativa do governo do Território. Os dois ensaios de colonização que não foram totalmente abandonados localizavam-se em terras macapaenses: a colônia de Matapi e a de Ferreira Gomes (IBGE, 1966, p.34).

Essa política de colonização era apresentada com muito entusiasmo pelo governo e pela imprensa regional. Em texto publicado em maio de 1954, o jornal Amapá citou um artigo publicado por um órgão da imprensa paraense, que caracterizou esta política como uma eficiente via para a superação de um modelo precário de ocupação do espaço, pois "o elemento humano, atingido pela malária e pela verminose foi encontrado às margens dos rios em grupos rarefeitos ou dispersos em agrupamentos de grande mobilidade, sobretudo à mineração do ouro, em precaríssimas condições de higiene". 0 texto acrescentava que a "administração colonizadora" estava melhorando no Amapá a agricultura e a pecuária por meio de "trabalho fecundo que tem por base o aproveitamento racional do solo por intermédio de colônias agrícolas e o melhoramento dos rebanhos através de uma assistência desvelada ao criador regional". Destacou as culturas do arroz, milho e mandioca, que, com a heveicultura, haviam recebido incentivos através de créditos ${ }^{4}$.

Recorrentemente, nos discursos de intelectuais e governantes, os ribeirinhos e rios amazônicos eram associados à ideia de atraso social, enquanto as rodovias e colônias agrícolas eram apresentadas como sinônimo de progresso pessoal e coletivo. Em meado do século XX, os principais meios de transporte na Amazônia eram as embarcações (de diversos tipos e tamanhos) e os rios eram os caminhos mais utilizados pelos moradores da região. Mas, para as classes dirigentes (nos níveis federal, regional e territorial), a modernização da sociedade local dependia da construção de uma rede rodoviária que tornasse mais rápido o deslocamento de pessoas e mercadorias e que funcionasse como meio de integração socioeconômica. Na perspectiva governamental, era imprescindível concentrar a população em colônias ou agrovilas, situadas próximas das cidades ou nas margens das rodovias, para liberá-la da influência centrífuga da dispersão dos recursos florestais. Assim, Amazônia das rodovias era apresentada como superior em relação àquela dos rios não apenas pela velocidade de seus fluxos, mas também por favorecer o aparecimento de núcleos de população agrícola, em franco contraste com a dispersão ribeirinha, derivada do extrativismo (Bomfim, 1954, p. 14-47).

\section{A espera do rio}

Entre 1944 e 1987, a capital do Amapá constituiu uma série de novas conexões com povoados e vilas do interior (do centro, do norte e do sul) do novo território, bem como reforçou e ampliou aquelas que já tinha com as ilhas da foz do Amazonas. No quadro do comercio nacional, Belém

\footnotetext{
${ }^{3}$ Antes do início da exportação do manganês, Macapá já era o mais importante centro consumidor amapaense (o que fica evidente na participação da capital no volume de importações territoriais). Não obstante, Mazagão era, então, o polo que gerava mais riquezas e volume de exportação (ver: Comércio do Amapá por vias internas: exportação em 1947. Amapá. № 170, de 12 de junho de 1948, p. 4-5; e Comércio do Amapá por vias internas: importação em 1947. Amapá. № 171, de 19 de junho de 1948, p. 4).

${ }^{4}$ Ver: Uma política racional de trabalho de fixação do homem ao solo. Amapá. № 531, de 01 de maio de 1954, p. 3.
} 
era o principal centro intermediário das trocas. Por exemplo, de 707 milhões de cruzeiros correspondentes às exportações de 1964, para todo o Brasil, 595 milhões foram destinados ao Pará. Quanto às importações, muito mais amplas, o Pará participou com 2,9 bilhões de cruzeiros, num total de 4,8 relativos a todo país. A este respeito, o Atlas do Amapá destacou:

Belém envia para Macapá alguns produtos que saem de suas indústrias, como, óleo de côco, colchões, calçados grosseiros, pregos, terçados, trincos, cimentos, panelas. Belém envia também bujões de gás engarrafado utilizado como combustível nas habitações de melhor nível econômico (a grande maioria se utiliza de lenha). Mas, a maior parte de suas mercadorias são originadas no sul ou foram simplesmente redespachadas em Belém ou sofreram uma operação comercial em Belém. Esta função de Belém como centro intermediário tende a se ampliar pela influência da rodovia Belém-Brasília: a estrada permite maior inundação de produtos provenientes do Brasil metropolitano, antes retida pelas dificuldades apresentadas no transporte marítimo. Existem já mais de trinta companhias de transporte rodoviário em Belém e mesmo em Macapá acham-se instaladas três. A capital paraense passa a ser um ponto de trançado, local de passagem das mercadorias de via terrestre para a via fluvial para atingir Macapá e, daí, outros locais do Território do Amapá (IBGE, 1966, p. 38).

Este texto destaca importantes transformações e tendências na estruturação da rede urbana amazônica: o aparecimento de uma nova forma de conexão entre a rede polarizada na capital paraense e as metrópoles nacionais; a intensificação do fluxo de mercadorias do sul em direção ao norte do Brasil; a consolidação de Macapá como polo mediador das relações econômicas entre Belém e os demais núcleos urbanos amapaenses; e a intensificação da circulação rodoviária também na rede polarizada em Macapá. Nos próximos parágrafos, pretendemos relativizar e problematizar alguns aspectos destas mudanças. No conjunto, elas estão diretamente atreladas aos processos de "rodovialização" e de formação de cidades médias na Amazônia. Tais processos impactaram a rede urbana previamente existente. Esta possuía, segundo a historiografia, duas características básicas, constituídas durante mais de três séculos: a adoção dos rios, principalmente do Amazonas e de seus afluentes, como meios de conexão e de circulação socioeconômica; e a macrocefalia urbana, ou seja, a grande disparidade entre a metrópole regional (ou sub-regional) e os demais aglomerados humanos (pequenas cidades, vilas e povoados).

Conforme expusemos anteriormente, não obstante a crescente polarização macapaense, os municípios interioranos mantiveram fortes conexões econômicas com Belém, graças à atuação direta de empresas belenenses e à força atrativa da praça comercial existente na capital do Pará. 0 livro Consultoria de Planejamento Urbano, Arquitetura e Turismo argumenta que um importante problema urbano do Território Federal Amapá residia "no grande isolamento geográfico provocado pela foz do rio Amazonas e rio Pará, que seccionou os vetores dinâmicos que espalharam o desenvolvimento em torno de Belém e o nordeste do Pará, calcados no ágil e prático transporte rodoviário e nos resultados positivos da exploração agrícola e pecuária". E acrescenta que Macapá somente consolidou-se como cidade em razão de sua condição de capital do Território e, portanto, dos investimentos recebidos do governo federal. Porém, o rio que separava também religava, pois sobre os cursos d'água corriam os mais vigorosos e frequentes fluxos socioeconômicos. As pequenas cidades do Amapá estruturavam-se a partir de uma rua principal (beira de cais) e de outra perpendicular, pontos de partida de uma malha ortogonal de vias "carroçáveis" ladeadas por casas de madeira e cobertas com palhas. Essas ruas principais concentravam o 'ânimo' local de núcleos que viviam à espera do que, pelo rio, poderia chegar (H. J. Cole Associados S.A, 1979, p. 17).

No conjunto das ações do governo territorial para fortalecer a primazia da capital amapaense, destacam-se os investimentos do Serviço de Transportes do Território Federal do Amapá (Sertta) no sentido de ampliar o número de embarcações e de linhas regulares de circulação fluvial. Em 1950, quase todas as linhas existentes tinham Macapá como ponto de partida. Poucos anos depois, a Enciclopédia dos Municípios Brasileiros destacou a enorme quantidade e variedade de embarcação que aportavam em Macapá, conectando esta cidade a pequenos povoados regionais e a grandes polos internacionais: "todas as localidades ribeirinhas do município se comunicam, por meio dos mais diversos tipos de embarcações, com a cidade de Macapá e esta com Belém e as cidades vizinhas". Embarcações como: "cargueiros de grande capacidade, oriundos de portos norte-americanos, 
conduzindo toda sorte de materiais especializados; navios transportadores de minérios que vêm carregar manganês; vapores do tipo 'gaiola', da navegação regional, iates a motor e vela e uma vastíssima flotilha de canos, barcos e veleiros, demandam normalmente o porto macapaense" (IBGE, 1957, p. 32).

Mas, o desenvolvimento qualitativo e quantitativo da frota do governo territorial não foi um processo linear ou contínuo, pois longas crises mais de uma vez abateram profundamente o setor de transporte marítimo regional e local. Em 14 de outubro de 1950, o jornal Amapá transcreveu um artigo que descrevia a precaríssima situação do Serviço de Navegação e Portos do Pará (Snapp), dando destaque a problemas como: poucas e precárias embarcações (apenas 13), uma dívida enorme e o assoreamento do Porto de Belém (que ocasionava constantes encalhamentos)..$^{5} \mathrm{Um}$ mês antes, este mesmo jornal havia lastimado a irregularidade com que o Snapp vinha mantendo a linha mensal Belém-Oiapoque. Esta, além estar fora de funcionamento havia meses, não correspondia em número de viagens e tonelagem à demanda territorial (que havia triplicado nos últimos 5 anos). 0 articulista também ressalta que as embarcações de tal linha transportavam exclusivamente as cargas do governo (para as quais já eram insuficientes), sobrando pouco espaço para o transporte de cargas e passageiros particulares (o que também era feito por elas). As ubás do governo territorial completavam o serviço das embarcações maiores, indo onde estas não podiam ir, por causa de seu tamanho ${ }^{6}$.

A crônica insuficiência de embarcações de médio e grande calado na Amazônia, fez com que, em 1953, o Presidente Getúlio Vargas autorizasse, em caráter excepcional, a compra de 9 navios para completar a frota de navegação no vale amazônico. Em janeiro de 1957, o Amapá noticiou que o Presidente Juscelino Kubitschek (JK), atendendo a um pedido de Janary Nunes, determinara ao Snapp a criação de uma linha Belém-Macapá, que deveria ser servida por um grande navio, com viagens pelo menos quinzenais. Já no mês seguinte, este periódico noticiou que JK tinha autorizado uma viagem quinzenal de uma chatinha entre Belém e Macapá, bem como uma mensal de um navio maior na linha Belém-Macapá-Amapá-Oiapoque-Caiena ${ }^{7}$.

Nos primeiros anos da década de 1960, o setor de transportes fluvial e marítimo entrou novamente em profunda crise. Em maio de 1963, Elias do Oliveira Júnior, no artigo intitulado "Entre muitas coisas. Amapá: terra esquecida", asseverava que o presidente da República deveria olhar com mais atenção para esse Território, "em face das dificuldades nos recebimentos de suas verbas, por sinal, excessivamente escassas, principalmente levando-se em conta o que ele rende ao País: aproximadamente trinta milhões de dólares [oriundos da exportação do manganês]".8 No final do ano seguinte, o Amapá afirmou que o governador Luís Mendes encontrara a frota do Sertta em um estado "triste, desolador e sombrio". E completou: "o legado desanimador deixado ao atual governo foi sumamente constrangedor -2 embarcações (o rebocador Araguari e o iate São Francisco) trafegando precariamente e as 14 outras jogadas ao abandono, e apodrecendo e

\footnotetext{
${ }^{5}$ Gravíssima situação dos transportes fluviais na Amazônia. Amapá. № 292, de 14 de outubro de 1950, p. 4. Em artigo do jornal Amapá de outubro de 1951, lemos a avaliação que o Diretor Geral do Departamento de Portos, Rios e Canais fez a propósito dos ancoradouros da Amazônia, "que, a seu ver, são todos dignos de lástima pelo estado deplorável em que se encontram". Este diretor deu como exemplo o assoreamento no porto belenense, destacando que os serviços para solucionar este problema iniciariam em poucos dias. Ressaltou a necessidade do estudo aero fotográfico do arquipélago do Marajó, visando a desobstrução dos rios aí existentes (Dignos de lástima os todos os portos da região amazônica. Amapá. № 344, de 20 de outubro de 1951, p. suplementar).
}

${ }^{6}$ A respeito das linhas mantidas pelo Sertta, este artigo destaca que: o iate Itaguary fazia o transporte marítimo (faixa norte) de materiais de construção para Amapá e Oiapoque e no retorno trazia o gado; a lancha a motor "Amapá" fazia mensalmente o transporte fluvial (faixa sul), indo de Belém a Macapá, com retorno passando pelo Jari; a alvarenga Uaçá e o rebocador Araguari atuavam no transporte de cargas de Belém para Macapá; o iate a motor São Raimundo atuava no abastecimento carne de gado para Macapá e eventualmente levava cargas outras (para escolas interioranas, por exemplo); e o lanchão Veiga Cabral transportava óleo diesel e (mais recentemente) madeiras vindas do Pará e dos interiores do Território (Serviços Industriais. Amapá. № 287, de 13 de setembro de 1950, p. 6.).

${ }^{7}$ Ver: Navegação do vale amazônico. Amapá. № 426, de 02 de abril de 1953, p. 4; Navio dos Snapp fazendo linha Belém-Macapá. Amapá. № 801, de 10 de janeiro de 1957, p. 6; e Viagem Belém-Macapá por navios do Snapp. Amapá. № 812, de 21 de fevereiro de 1957, p. 1.

${ }^{8}$ Oliveira Jr., Elias do. Entre muitas coisas - Amapá: terra esquecida. Amapá. № 1219, de 22 de maio de 1963, p. 4. 
ao sabor de mãos criminosas que nelas praticavam a mais sórdida pirataria" e que "enquanto isso, era total a desassistência ao interior". ${ }^{9}$ Essa situação de crise (que era, entre outras coisas, um desdobramento de um momento crítico da economia nacional) apenas foi revertida nos últimos anos da década de 1960. No contexto do "milagre brasileiro", pesados investimentos foram feitos para o melhor aparelhamento da frota territorial, com a compra de embarcações de grande calado e de motores à diesel, tendo em vista a padronização das embarcações. ${ }^{10}$

Analisar os avanços e limitações da política de ampliação e manutenção de linhas do transporte marítimo amapaense é um passo fundamental para entendermos a fragilidade da primazia de Macapá no período estudado. Mas, não podemos deixar de enfocar outros sujeitos (não vinculados diretamente ao Estado) que, se valendo desta mesma fragilidade criaram e sustentaram fluxos e conexões regulares entre a capital amapaense e outros núcleos populacionais. Era à sombra da secular Fortaleza de São José que a maioria das embarcações (ubás, gaiolas, lanchas, etc.) de pequenos comerciantes independentes parava. Em 1955, por exemplo, 4.704 barcos aportaram nesta doca, conforme dados oficiais. Isto representa uma média de aproximadamente 78 embarcações por semana (Costa, 2008, p. 98). Muitos destes barcos pertenciam a regatões que mercadejavam entre Macapá, Belém, ilhas da foz do Amazonas e interiores do Pará e do Amapá. Estes mascates fluviais desempenhavam um papel fundamental no abastecimento da praça macapaense. Isto porque as embarcações do Serviço de Navegação do Amapá (Sertta-Navegação) eram frequentemente encostadas no estaleiro governamental, onde aguardavam reparos ou reformas de efeito meramente paliativo. Por outro lado, somente as embarcações com carga inferior a 10 mil quilos conseguiam atracar nesta doca, pois seu canal navegável era raso. ${ }^{11} \mathrm{E}$, ainda que respeitasse tal limite, o marítimo deveria esperar a maré alta - caso contrário, poderia ficar encalhado. Portanto, o "pinga-pinga" do comércio de regateio era responsável por boa parte dos víveres consumidos pelos moradores de Macapá (Costa, 2008, p. 200-201).

\section{As promessas da estrada}

Macapá não comandava a entrada de um vale que possibilitasse a interiorização de sua influência. Portanto, foi pelas águas do Amazonas que esta cidade primeiramente tentou estender as linhas que a colocariam em contato com os demais núcleos urbanos. Entretanto, como ressaltamos acima, a costa oceânica (o limite nordeste do Território) exigia cuidados especiais no tráfego marítimo. Entre outros fatores, essas dificuldades justificavam o investimento na construção de uma estrada de rodagem que ligasse o sul ao norte do Território do Amapá. Assim, em 30 de novembro de 1946 foi divulgada a aprovação do Plano Rodoviário do Amapá, que previa, além da Macapá-Clevelândia, as rodovias de Macapá de à nascente do Jari e à vila chamada de Boca do Jari (esboçando uma rede centrada na capital), bem como a ligação Amapá-Calçoene-CunaniCassiporé. Mas, a execução do plano abrangeu a construção de várias outras estradas vicinais, ampliando as possibilidades de conexão horizontal (entre pequenas cidades e vilas) dentro dos limites territoriais. ${ }^{12}$

Em agosto de 1947, foi noticiado com entusiasmo o trânsito de gado do município de Amapá para a colônia de Ferreira Gomes pela picada aberta para a construção da Macapá-Clevelândia. ${ }^{13} \mathrm{E}$ em julho de 1950, o governador Janary Nunes pôde percorrer a então chamada APBR-15 (futura BR-156), indo de Macapá a Porto Grande, e depois ao Tartarugalzinho. As obras evoluíam nos dois sentidos (do sul para o norte e vice e versa). ${ }^{14}$ Partindo da constatação de que a população territorial se concentrava em núcleos localizados na costa amapaense ou em pontos não distantes dela (tornando-se

\footnotetext{
${ }^{9}$ Inoperância e descaso afundam (em terra) a frota do Sertta. Amapá. № 1303, de 19 de dezembro de 1964, p. 1-3.

${ }^{10}$ Governo modernizará a frota da Susnava beneficiando o interior. Amapá. № 1462, de 06 de janeiro de 1968, p. 3.

${ }^{11}$ As embarcações mais pesadas atracavam na Baixa do Mucura, localizada do lado direito da Fortaleza, numa área pouco povoada chamada de Elesbão (atualmente o bairro Santa Inês). Fazia fronteira com a Vacaria — lugar assim chamado porque nele criava-se gado, extensivamente.

${ }^{12}$ Aprovado o Plano Rodoviário do Amapá em 1946. Amapá. № 94, de 04 de janeiro de 1947, p. 1.

${ }^{13}$ Gado de corte dos campos pastoris do Amapá já pode vir a este município por via terrestre. Amapá. № 127, de 16 de agosto de 1947, p. 4.

${ }^{14}$ Percorre o interior amapaense, em inspeção, o governador do Território. Amapá. № 280, de 22 de julho de 1950, p.6.
} 
muito rarefeita na parte ocidental), os membros da classe dirigente local insistiam na importância desta rodovia como fator de povoamento do interior. No jornal Amapá de 13 de setembro de 1951, o articulista afirma que o investimento do governo na construção de rodovias derivava do fato do Território ter uma população estabelecida em núcleos distantes uns dos outros e dependentes de uma navegação marítima difícil na faixa oceânica. Ele argumenta que a construção da MacapáClevelândia era um fator importante de progresso para o Amapá e que esta rodovia:

foi se estendendo pelas regiões antes desertas, qual artéria vital de progresso, desenrolando-se rumo ao norte, levando consigo escolas, postos médicos, saneamento, pontes, abastecimento, vitalidade, progresso, ligando pequenas povoações, onde a pecuária e a agricultura eram primitivas para transformá-las em fontes perenes e onde já pontificam o zebu e onde os tratores e arados sulcam a terra para a cultura do fumo e do arroz, reduzindo os trinta dias de transporte penoso a cavalo e à pé, para três horas de automóvel luxuoso e confortável ${ }^{15}$.

Segundo o discurso hegemônico, por meio das rodovias, o "progresso" chegaria à hinterland amapaense. Progredir seria então abandonar um modo de vida e trabalho baseado em tradições indígenas, no extrativismo, na agricultura de subsistência realizada com técnica "rudimentar"16. Seria também tornar-se sedentário e em agrovilas ter acesso à educação escolar e à medicina científica. 0 Jornal do Comércio (Rio de Janeiro), em 1952, fez o seguinte comentário sobre o Plano Rodoviário do Amapá: "hoje, Amapá e Macapá, que são os principais municípios do Território, distantes cêrca de 400 quilômetros, podem ser ligados em poucas horas de viagem, por confortável rodovia". E mais: "as estradas amapaenses, como bem acentuou recentemente e imprensa local, traduzem de 'quilômetro em quilômetro' o incentivo e a facilidade para a educação, o radicamento e a nova atração do homem ao solo, à produção e ao abastecimento, a riqueza e a felicidade de um povo"17. Nas páginas do jornal Amapá, a BR-156 era apresentada como "um grande fator civilizador" e como um "veículo portador de cultura e de novos métodos de vida para povos pouco desenvolvidos"18.

Não obstante esse discurso entusiasta, apenas na década de 1980 ensaiou-se executar um sistemático processo de povoamento e colonização das margens da BR-156. Antes disso, a Divisão de Terras e Colonização distribuía licenças de ocupação e uso de terrenos, mediante requerimento prévio. Apenas em maio de 1984, o Instituto Nacional de Colonização e Reforma Agrária (Incra) aprovou o projeto de colonização das margens da BR-156, enviado dois anos antes pelo governo territorial. A meta governamental era então assentar 3500 famílias na área desapropriada por aquele Instituto. Os principais objetivos do projeto eram: "absorção e fixação ao solo de pequenos produtores sem terra; ocupação racional e utilização eficiente de vazios demográficos; expansão da fronteira agrícola e criação de condições básicas, visando o aumento da produção, da produtividade e da oferta de alimentos". 0 projeto estimava que os problemas de adaptabilidade seriam minimizados pelo fato da maioria da clientela ser oriunda da região. Ele deveria ser executado pela Divisão Técnica Territorial, com supervisão da Coordenadoria Regional do Incra ${ }^{19}$.

Após analisarmos as licenças concedidas pela Divisão de Terras e Colonização, pudemos inferir que o trecho da BR-156 mais procurado pelos requerentes fora o que ficava entre Macapá e Ferreira Gomes. Trata-se do trecho da rodovia que, dentro do período estudado, apresentava melhores condições de trafegabilidade e fluxo mais intenso (frequência de circulação de veículos). Aí transitavam os caminhões e tratores da Icomi, que, portanto, colaborava com a manutenção de seu bom estado. ${ }^{20}$

\footnotetext{
${ }^{15}$ Plano Rodoviário do Território. Amapá. № 339, 13 de setembro de 1951 (2ª seção), p. 1 e 8.

16 No artigo do jornal Nôvo Amapá intitulado "Selva agreste está sendo vencida pelo homem", publicado em 07 de setembro de 1970, lemos o seguinte: "cada clareira aberta no seio da mata é um raio de esperança a mais que se descortina para aqueles que, longe das cidades, esperam pela estrada que virá abrir novos horizontes à economia amapaense e dar ao nosso caboclo novas condições de vida" (Selva agreste está sendo vencida pelo homem. Amapá. № 1585, de 07 de setembro de 1970, p. 8).

17 Transcrito em: Plano Rodoviário do Amapá. Amapá. № 363, de 01 de março de 1952, p. 1.

${ }^{18}$ Rodovia Macapá-Clevelândia: 627 quilômetros de estrada rasgando o coração da floresta. Amapá. № 504, de 25 de janeiro de 1954, p. 3.

${ }^{19}$ Projeto de colonização aprovado. Amapá informativo. № 13, de maio de 1984, p. 3.

${ }^{20}$ Colabora a Icomi na reconstrução da BR-15. Amapá. № 1180, de 13 de setembro de 1962.
} 
O otimismo em relação ao poder transformador da BR-156 era cotidianamente frustrado pelo lastimável estado da maior parte dela. Em agosto de 1963, o governador Terêncio Porto esteve reunido com o Ministro da Viação a quem reivindicou uma "solução rápida para os problemas das rodovias do Amapá 'que estão em situação lastimável e impedem, até mesmo, em alguns trechos, o tráfego normal dos veículos que abastecem os distritos pertencentes ao Território"'21. Um ano depois, o jornal Amapá apresentou uma síntese do relatório do diretor da Divisão de Obras, cujo título era "Em estado precário a rodovia AP-BR-15". Moacyr Paumgarttem afirmou que "a ausência de um sistema assíduo de manutenção permitiu que a vegetação tomasse conta do leito da estrada, causando séria ameaça ao trânsito". E destacou ainda: "há locais onde existe apenas uma trilha sulcada pelos veículos que por lá trafegam e outros que são verdadeiros atoleiros". 0 diretor advertiu que se medidas urgentes não fossem tomadas Calçoene poderia ficar isolada por via terrestre, com graves consequências para seus moradores ${ }^{22}$.

Em 1966, o Atlas do Amapá destacara que a rodovia BR-156 apresentava boas características até Ferreira Gomes e que, "no entanto, a estrada desde Paredão, ou desde Ferreira Gomes, para o norte, muda de característica, embora continue passando na sua maior extensão. Através dos cerrados, ela se torna intransitável com fortes chuvas". E ressalta que "este fenômeno é mais grave nos trechos em que a estrada atravessa terras de altitude muito baixa, nas proximidades do litoral". Além disto, o número de veículos que faziam a conexão com o norte do território era insuficiente, pois segundo o Atlas, a ligação de Amapá com Macapá era mantida por 2 caminhões particulares e 1 do governo, armados para o transporte de passageiros. Estes caminhões realizam apenas 4 serviços semanais. Portanto, os carros partiam sempre "apinhados de gente" e muitos perdiam a viagem por falta de lugar. Ou seja: "apesar da região apresentar baixas densidades econômicas, o transporte encontra-se em níveis ainda mais inferiores, abaixo das necessidades, afetando as possibilidades de envio de produtos agrícolas para o abastecimento de Macapá" (IBGE, 1966, p. 38).

Acompanhando um conjunto amplo de grandes obras realizadas no Amapá ${ }^{23}$ durante o período do chamado "milagre brasileiro" (Earp \& Prado, 2003), a BR-156 passou por um intenso processo de recuperação e de aceleração de sua conclusão. 0 articulista Sillas Assis escreveu no Amapá de 05 de outubro de 1968 que "a atual administração [do governador Ivanhoé Martins], ao ser instalada, analisou a situação da rodovia, nos seus diversos aspectos sociais, políticos e econômicos, e decidiu realizar um esforço considerável no sentido da sua conclusão". Assis destacou que o governo se empenhara no sentido de conseguir os meios para "imprimir um novo ritmo aos trabalhos da estrada" e que 458 quilômetros já estavam em condições de trafegabilidade, ligando Macapá à localidade de Tigre (Calçoene) e que o trabalho avançava do sul para o norte e vice-versa. ${ }^{24} \mathrm{Em}$ janeiro do ano seguinte, o governo decidira concluir a BR-156 o mais rápido possível, considerando esta rodovia "como instrumento de posse da terra, como agente do estabelecimento de polos de colonização e como fator fundamental para o aproveitamento de áreas dotadas de potencial produtivo ao longo do traçado ou na faixa de sua influência". Segundo o jornal Nôvo Amapá, "o Governo chegou à conclusão de que a rodovia deveria ser terminada dentro do mais breve espaço de tempo permitido pelos recursos técnicos e financeiros". Em janeiro de 1971, a ligação entre Macapá e Oiapoque pela BR-156 estava concluída ${ }^{25}$.

\footnotetext{
${ }^{21}$ Governador Terêncio de Mendonça Porto agradece ao "Jornal do Brasil" [pela] c apanha em favor do povo do Território Federal do Amapá. Amapá. № 1232, de 14 de agosto de 1963, p. 1.

${ }^{22}$ Estado precário da rodovia AP-BR-15. Amapá. № 1285, de 15 de agosto de 1964, p. 4.

${ }^{23}$ Eis alguns exemplos das obras governamentais realizadas no setor rodoviário: em agosto de 1970, o Nôvo Amapá divulgou a assinatura de um convênio (50 mil cruzeiros oriundos do Imposto Único sobre Minerais) entre a prefeitura de Mazagão e o governo territorial, visando a conclusão da rodovia Macapá-Mazagão (Velho sonho dos mazaganenses será realizado. Nôvo Amapá. № 1584, de 22 de agosto de 1970, p. 1); em novembro de 1970, ocorreu a inauguração da estrada asfaltada Duque de Caxias, que ligava Macapá a Santana, com 25 quilômetros de extensão (Inaugurada a mais bela estrada asfáltica do Território. Nôvo Amapá. № 1595, de 25 de novembro de 1970, p. 1); o Nôvo Amapá, em 14 de abril de 1973, noticiou o início da construção da estrada entre Santana e Fazendinha, ocorrido em 09 de abril de 1973 (Prefeitura liga Santana-Fazendinha. Nôvo Amapá. № 1679, de 14 de abril de 1973, p. 6); e em 22 de dezembro de 1973 foi inaugurada a Rodovia "Salvador Diniz" (Inaugurada a rodovia Salvador Diniz Santana-Fazendinha. Nôvo Amapá. № 1713, de 31 de dezembro de 1973, p. 8).

${ }^{24}$ Novo ritmo de trabalho na Macapá-Clevelândia. Nôvo Amapá. № 1495, de 05 de outubro de 1968, 3.

${ }^{25}$ BR-156 chega ao Oiapoque. Nôvo Amapá. № 1599, de 09 de janeiro de 1971, p. 3 e 4.
} 
No início de 1973, no contexto de regozijo pelo anúncio da construção da Perimetral Norte ${ }^{26}$, o relatório do Serviço de Estradas de Rodagem (Seer), que havia feito inspeção na BR-156, afirmou que esta rodovia, no trecho Macapá-Ferreira Gomes, apresentava, em média, boas condições de trafegabilidade, apesar do constante uso da pista por caminhões que transportavam cargas destinadas à construção da Hidrelétrica do Paredão. Por outro lado, o SER destacou que aí estava sendo realizado um permanente serviço de conservação. 0 trecho entre Ferreira Gomes e Amapá estava também ("em média") com boa trafegabilidade, "permitindo a passagem normal de qualquer tipo de veículo", bem como aquele entre Amapá e Calçoene. Todavia, de Calçoene a Lourenço, especialmente a partir do $\mathrm{km} \mathrm{46}$, a rodovia tornava-se precária "em face das constantes chuvas que desabam sobre a região" 27 .

No mês de janeiro de 1974, o Nôvo Amapá noticiou que o secretário de obras do Território, Joaquim de Vilhena Neto, estava pleiteando recursos junto Departamento Nacional de Estradas de Rodagem (Dner) para asfaltar 140 quilômetros da BR-156. Airton de Almeida, representante da Secretaria de Obras e Produção (SOP), declarou à reportagem do periódico que "mesmo com todo o esforço, os serviços de manutenção não atendem as necessidades, precisamente pelo volume do tráfego e pelas chuvas que tudo destroem"28. O Dner tinha acenado com a possibilidade de conceder recursos para o asfaltamento de 100 quilômetros daquela rodovia. Em junho de 1974, o jornal Nôvo Amapá destacou que "as chuvas, caindo torrencialmente na estrada BR-156 vem dificultando o trânsito naquela rodovia, principalmente o trecho denominado Água Branca" e que "o problema surge com mais intensidade às margens dos rios, quando as águas transbordam durante o inverno, com prejuízos assustadores para o tráfego, havendo mesmo ocasiões em que os carros são obrigados a parar até por um período de 12 horas, esperando que as águas baixem". 0 representante da SOP, Airton Almeida, afirmou que o problema só seria definitivamente resolvido com o asfaltamento de toda a rodovia, o que demandava tempo ${ }^{29}$. De fato: até hoje tal trabalho não foi terminado.

As chuvas e a falta de recursos são alguns dos motivos que explicam essa demora. 0 governador Annibal Barcellos, em 1980, explicou que a terraplanagem do trecho da BR-156 entre Calçoene e Oiapoque havia sido interrompida temporariamente "em consequência das chuvas torrenciais que castigavam a região nesta época invernosa do ano" e acrescentava de forma otimista que, "para a programação de 1980, dado o volume de trabalho previsto para ser executado, se faz necessária a aquisição de novas máquinas e que se trabalhe mesmo na época das chuvas para que a abertura do caminho de serviço que irá dar substancial apoio para que sejam atingidas as metas pré-estabelecidas" (Barcellos, 1980, p. 4). 0 Amapá informativo, em agosto de 1984, noticiou o prosseguimento da "gigantesca e desafiante" obra de asfaltamento da BR-156, destacando que, naquele ano, o governo pretendia pavimenta-la até o $\mathrm{km} 35^{30}$. A administração territorial estava realizando o asfaltamento desta rodovia praticamente com recursos próprios, pois o governo federal não repassara os 20 bilhões solicitados. Segundo o Amapá informativo, se isto tivesse ocorrido, o asfalto não teria chegado somente até o $\mathrm{km} \mathrm{32}$, mas ao $100^{31}$. Quando finalmente recebera as primeiras camadas asfálticas - 36 anos após o início de sua construção (1947), a parte sul desta rodovia (os 222 quilômetros do trecho entre a Cachoeira de Santo Antônio do Jari e Macapá) não estava ainda concluída ${ }^{32}$.

\footnotetext{
${ }^{26}$ Em artigo de 10.02.73, o jornal Nôvo Amapá ressaltou a importância do projeto de construção da Perimetral Norte. Nas palavras do articulista: "a Rodovia Perimetral Norte é vista pelas autoridades de segurança como mais importante que a Transamazônica, considerando que a fronteira norte do País é atualmente apenas controlada por via aérea e com grande dificuldade pelos rios". Destacou também o projeto de colonização elaborado pelo Incra, que faria, segundo ele, da Perimetral um eixo de povoamento de extensa faixa fronteiriça (Malha de estradas. Nôvo Amapá. № 1670, de 10 de fevereiro de 1670, p. 3).

${ }^{27}$ Seer realiza inspeção na rodovia BR-156. Nôvo Amapá. № 1669, de 03 de fevereiro de 1973, p. 4.

${ }^{28}$ SOP recupera estrada e vai tentar asfaltamento. Nôvo Amapá. № 1715, de 19 de janeiro de 1974, p. 4.

${ }^{29}$ Chuvas interrompem o tráfego na BR-156. Nôvo Amapá. № 1722, de 16 de março de 1974, p. 1.

${ }^{30}$ Reiniciado asfaltamento da BR-156. Amapá informativo. № 16, de agosto de 1984, p. 4.

${ }^{31}$ Asfaltamento da BR-156. Amapá informativo. № 20, de dezembro de 1984, p. 10.

${ }^{32}$ Asfalto da BR-156 começa com Barcellos. Amapá informativo. № 2, de 30 de maio de 1983, p. 9.
} 
Certamente a BR-156 não atingiu as suas metas mais arrojadas. No período estudado, o tráfego de veículos tornava-se irregular e fraco a partir de Ferreira Gomes e quase impossível (sobretudo nos períodos chuvosos) entre a cidade de Amapá e Oiapoque. Como ressaltamos, sua transformação num eixo de formação de novos povoamentos e campos agrícolas tornou-se fato apenas no trecho entre a capital e a sede do município de Amapá. A lenta intensificação das trocas entre estes dois núcleos urbanos amapaenses foi a transformação mais importante que aquela rodovia produziu. Trata-se do tímido (mas relevante) começo do exercício de uma efetiva influência macapaense em uma área que quase deixou de ser parte do Brasil.

\section{Palavras finais}

No período analisado, as conexões que ligavam Macapá aos aglomerados humanos do Território do Amapá e das ilhas da foz do Amazonas multiplicaram-se, ainda que este aumento não tenha ocorrido de forma contínua. Os circuitos (marítimo-fluviais, terrestres, aéreos e de telecomunicações ${ }^{33}$ ) pré-existentes, assim como os novos, tiveram seus fluxos intensificados, malgrado os fortes e por vezes prolongados períodos de crise no setor de transporte regional e territorial. Aliás, como demonstramos anteriormente, a irregularidade e a precariedade dos transportes marítimo-fluviais mantidos pelo Sertta concorreram para que os regatões se tornassem agentes fundamentais do abastecimento da capital amapaense, ligando-a ainda mais aos demais aglomerados do Território, às ilhas marajoaras e a Belém. Macapá tornou-se, portanto, uma cidade intermediadora ou redistribuidora (de bens, serviços, deslocamentos humanos, etc.) dentro da rede urbana regional.

Ficou evidente a fragilidade das novas conexões entre Macapá e os demais núcleos urbanos, sobretudo os do extremo-norte amapaense. 0 estado frequentemente inservível do trecho da BR-156 situado entre as cidades de Amapá e Oiapoque concorreu para que a influência macapaense aí permanecesse fraca. Outro fator de manutenção desta fraqueza era a precariedade e inconstância dos serviços de transporte marítimo-fluvial. A pré-existência de relações comerciais entre pescadores e pecuaristas do norte do Território e as praças de Belém e de Caiena nos levam a inferir que as pequenas cidades amapaenses não raramente prescindiam da mediação de Macapá. Em meado do século XX, a atuação de empresas de exploração do extrativismo vegetal em Mazagão fazia com que a maior parte da produção deste município escoasse diretamente para a capital paraense. Assim, a polarização de Macapá não era absoluta: ela se fazia sentir de forma desigual e não se ampliou com o mesmo vigor, constância e eficácia em todas as áreas que hoje compõem sua rede urbana sub-regional.

\section{Referências}

Abenon, L., \& Dickinson, J. A. Les français en Amérique. Lion: Presse Universitaire de Lion, 1993.

Amaral, M. D. B. (2010). Dinâmicas econômicas e transformações espaciais: a metrópole de Belém e as cidades médias da Amazônia Oriental - Marabá e Macapá. Tese de Doutorado [Geografia], Universidade de São Paulo, São Paulo, SP, Brasil.

Andrade, T. A., \& Lodder, C. A. (1979). Sistema urbano e cidades médias. Rio de Janeiro: Instituto de Pesquisa Econômica Aplicada.

Araújo, R. M. de (1998). As cidades da Amazônia no século XVIII: Belém, Macapá e Mazagão (2a. ed.). Porto [Portugal]: FAUP.

\footnotetext{
${ }^{33}$ Entre 1944 e 1987 ocorreu no Território do Amapá uma ampliação e um aprimoramento técnico das redes de telégrafo, exemplo: de telefonia e de rádio (por exemplo, no dia 04 de agosto de 1973, o Nôvo Amapá noticiou que o Plano de Telecomunicações do Território iria instalar 23 pontos de telefonia no Amapá (Plano de Telecomunicações em vias de conclusão. Nôvo Amapá. № 1695, de 04 de agosto de 1973, p. 4). Ademais, em 15 de junho de 1974, o Nôvo Amapá divulgou a inauguração da TV no Amapá (Inauguração da tv foi uma festa geral. Nôvo Amapá. № 1734, de 15 de junho de 1974, p. 6).
} 
Araújo, R. M. de, \& Moreira, R. (1999). A engenharia militar do século XVIII e a ocupação da Amazônia. In Amazônia Felsínea: António José Landi: itinerário artístico e científico de um arquitecto bolonhês na Amazônia do século XVIII (pp.173-196). Lisboa: Comissão Nacional para os Descobrimentos Portugueses.

Barata, M. (1973). Formação histórica do Pará. Belém: Universidade Federal do Pará.

Barcellos, A. (1980). Amapá 1ํo ano de gov. Cmte. Annibal Barcellos. Macapá: Do autor.

Bastos, A. de M. (1947). Uma excursão ao Amapá. Rio de Janeiro: Imprensa Nacional.

Bezerra, A. (2008). A margem esquerda do Amazonas. Fortaleza: Premius.

Bomfim, S. (1954). Um esboço da vida amazônica. In SPVEA [Brasil]. Valorização Econômica da Amazônia: subsídios para o seu planejamento (pp.14-47). Rio de Janeiro: Departamento de Imprensa Nacional.

Browder, J. O., \& Godfrey, B. J. (2008). Cidades da floresta: urbanização, desenvolvimento e globalização na Amazônia brasileira. Manaus: UFAM.

Cabreira, M. M. (1996). Vargas e o rearranjo espacial do Brasil: a Amazônia brasileira - um estudo de caso. Dissertação de Mestrado [Geografia Humana], Universidade de São Paulo, São Paulo, SP, Brasil.

Carvalho Jr., A. D. de (2013). A ordem da missão e os jogos da ação: conflitos, estratégias e armadilhas na Amazônia do século XVII. Tempo, 19 (35), 23-41.

Castro, E. (2008). Urbanização, pluralidade e singularidades das cidades amazônicas. In E. Castro (Org.). Cidades na floresta. São Paulo: Annablume.

Cole, H. J. Associados S.A. [Brasil]. (1979). Consultoria de planejamento urbano, arquitetura e turismo. Documento síntese, Rio de Janeiro.

Correa, R. L. L. (1987). A periodização da rede urbana da Amazônia. Revista Brasileira de Geografia, 49 (3), 39-68. [Rio de Janeiro, Ano 49].

Costa, P. M. C. (2008). Na ilharga da fortaleza, logo ali na beira, lá tem o regatão: os significados dos regatões na vida do Amapá (1945-1970). Belém: Açaícu.

Cunha Jr., A. J. da, \& Genschow, F. A. (1958). Amapá: um estudo para a colonização. Rio de Janeiro: INIC.

Dias, E. M. (2007). A ilusão do fausto - Manaus - 1890-1920 (2a. ed.). Manaus: Valer.

Drummond, J. A., \& Pereira, M. de A. P. (2007). O Amapá nos tempos do manganês: um estudo sobre o desenvolvimento de um estado amazônico - 1943-2000. Rio de Janeiro: Garamond Universitária.

Earp, F., \& Prado, L. C. D. (2003). 0 "milagre" brasileiro: crescimento acelerado, integração internacional e concentração de renda (1967-1973). In J. Ferreira \& L. de A. N. Delgado (Orgs.). O Brasil Republicano: o tempo da Ditadura: regime militar e movimentos sociais em fins do século XX. Rio de Janeiro: Civilização Brasileira.

Gama, A. (1947). Um rio a serviço de dois povos. Belém: Gráfica da Revista da Veterinária.

Guedes, G., Costa, S., \& Brondízio, E. (2009). Revisiting the hierarchy of urban areas in the Brazilian Amazon: a multilevel approach. Popul Environ, 30, pp. 159-192.

Greissing, A. (2012). La région du Jari: un laboratoire en Amazonie. Thése de doctorat en Géographie soutenue à l'Université Sorbonne Nouvelle (Paris 3).

Guerra, A. T. (1954). Estudo geográfico do Território do Amapá. Rio de Janeiro: IBGE.

(C) Labor \& Engenho, Campinas [SP] Brasil, v.11, n.2, p.176-190, abr./jun. 2017. 
IBGE [Brasil] (1957) Enciclopédia dos municípios brasileiros. Rio de Janeiro: Instituto Brasileiro de Geografia e Estatística.

IBGE [Brasil] (1966) Atlas do Amapá. Rio de Janeiro: Instituto Regional de Desenvolvimento do Amapá e Conselho Nacional de Geografia (IBGE).

Lobato, S. (2011). Os descaminhos da fortuna: a política de colonização no Amapá (1940-1958). In S. Lobato et al. (Orgs). Do lado de cá: fragmentos de história do Amapá (pp.115-138). Belém: Açaí.

Nunes, O. (1950) Introdução ao Estudo da Amazônia brasileira. Rio de Janeiro: Ministério da Guerra.

Reis, A. C. F. (1953). O seringal e o seringueiro. Rio de Janeiro: Serviço de Informação Agrícola.

Santos, E. R. C. (2012). Amazônia Setentrional Amapaense: do "mundo" das águas às florestas protegidas. Tese de Doutorado [Geografia]. Universidade Estadual Paulista "Julio de Mesquita Filho" [Unesp], Rio Claro, SP, Brasil.

Weinstein, B. (1993). A borracha na Amazônia: expansão e decadência (1850-1920). São Paulo: Hucitec.

\subsection{Jornais e Revistas}

Amapá (Nôvo Amapá a partir de 1968), números de 1945 a 1974.

Amapá informativo, números de 1983 a 1984.

ICOMI notícias, números de 1964 a 1967. 